HEAVY-ION BEAM SOURCE

FOR

R H I C

A. G. Ruggiero

(BNL, January 17, 1984) 
SUIMGRY

In thi note we describe a scheme to obtain a high perromance relasiviatic heavy ior collider (Fite) of a size which fits the present CEA turne1 at ENL.

The project is made of two parts: the source of treavy iors and the Colidder itself. We Iitee to heep these two parte well separated Since different kind of work analysig $i=$ to be dore for each of them: but yet it is obvious that the performaree of ome of lhem ceperde crucially on the performance of she other.

\title{
THE SDURCE
}

\author{
This, in turn is mace of the following perts \\ 1. The repative-ion souree \\ E. The Tanden vardeorate \\ 3. The Eovats Ristg \\ 4. The AGS.
}

The proposed rew additim to the ENL racilities is the Ewostor" Ring. There are also included trensfer lines that go from the

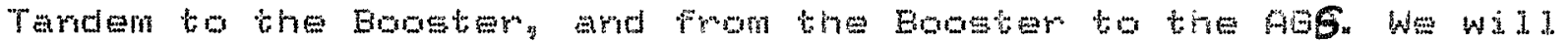
rot cover the desigr of these shemeport in ines.

\section{The Negative-Ior Bource}

The elemerts that have beer proposed are giver in Table i These elements are adequate to cover most of the experimemal program with the colidider since their atomic mase varies like ra with $n$ an integer. They have also been choser becuse frey man be easily produced as regative-ions to be fed into the fource for the Taridern:

Typical currerts that car be gererated at the source for these elemerts $i s$ around equ micho-amp-perticie, except for ceuterium for which we can expect as much as ore mili course protore are gererated by a different and hither intersity mources the eab MeV Lirace.

\section{E. The Tardem variegrabr}

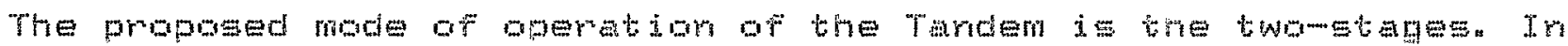

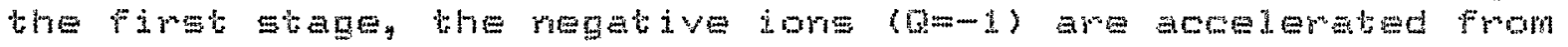
ground to a +15 wh potertian ot this point the hiretic energy ot 
Table 1. Proposed Elements for RHiC

Element (n) Atomic No. Mass No, Rest Energy $A / Z$

$\begin{array}{llllll}\text { Proton } & (1) & 1 & 1 & 0.9383 & 1.0 \\ \text { Deuterium } & (1) & 1 & 2 & 0.9375 & 2.0 \\ \text { Carbon } & (2) & 6 & 12 & 0.9310 & 2.0 \\ \text { Sulphur } & (3) & 16 & 32 & 0.9302 & 2.0 \\ \text { Copper } & (4) & 29 & 63 & 0.9299 & 2.2 \\ \text { Iodine } & (5) & 53 & 127 & 0.9302 & 2.4 \\ \text { Gold } & (6) & 79 & 197 & 0.9308 & 2.5\end{array}$




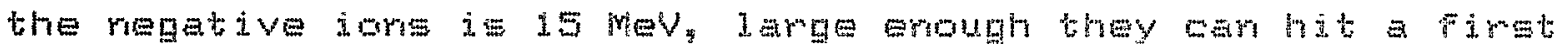
stripping tanget located in the high-voltage teminal. The mos

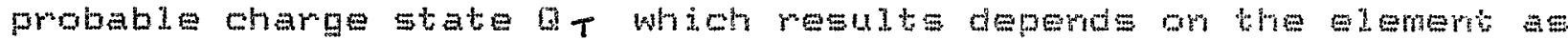

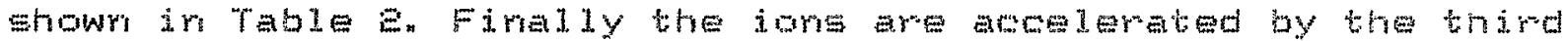

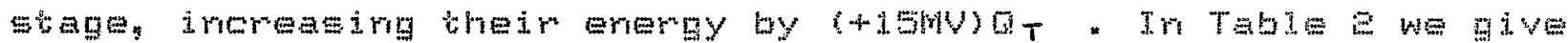
also the most probable chamge stabe Gf of the icris after one nore ( and last, stripping target located at the end of the Tanden. of course there is no reed for the eecond target in the case of the deuterium beang siree it was completely gtripped at whe first target.

The expected Etripping efficiencies ST and SF ame al w giver ir Table E. The Tarden output curmerts are calculated by tabiro irto mccourt the stripping efficiencies and ar overall Tandem

trarismissior efficiercy of $75 \%$.

The following cycle is proposed: the pulse lergth is at most tob micro-see long, ard the repetition period $i \leq 1.2$ secto mesch the Booster Ring arid the AGS cycies.

There are good experimertal eviderices thet sugest the beam quality s intersity, emittarce and emergy spready remains

constart over the length or the pusew more experimental work is planred to coormoborate thi fact for any element chomen In the meartime we assune for the purpose or our desin that this is trutu.

At the end of the Tandmy atom the Iast stage or stripping the total beam emithance does rot exceed $2 \pi$ mm-mod and the reistive kinetic energy spread is arourd 12 -4 "mostiy due to power gupply regulation Enrors. Again we aseune that this applises for any enement choser.

The beam; to be captured by the simale rif bueket in the Eooster. has to be pre-burched. We assume that the bumching factor over al

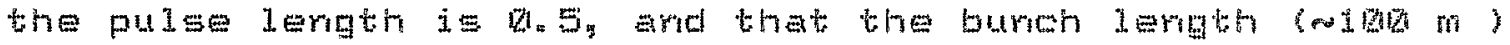
equals half of the Eooster cimcumfererce. Therefore the distsmon center-tomerter, betweer bunches will be twice that. We aseume also that the bunching $i$ : $10 \% \%$ efricient, and wid catse an ifcrease of the beam erroy spread by a factor 2 or 3

\section{The Emoster Ning}

The eircumference of this ring is just one qumber of tre Ags cimeurnference. The most importamt parameters are 1 istod in Table 3

We assume that the betwtrom acceptance is $50 \pi$. mm-mma in both planean It could be langer in the horizortal pianen but very Iikely the extra mourt is rot useful because of linear and ron lirear coupling between the two mode of becil lations. The bean $i=$ injected into the Eooster and stacked in she betathon phase space by wrapping the machime ex reuferemce with the beam pulse for some number $n$ of correcutive turres which corferesponds to a total rumber of particles $N_{B}$. It is assumed thet the beam will Fil up quickly the avaluble acceptares in both plares with the help evertualiy of other available eteering means, unil the spece 
Table 2. Tandem Operation Parameters *

\begin{tabular}{l|cc|cc|cc|c} 
Element & $Q_{T}$ & $S_{T}$ & $\begin{array}{c}\text { Kinetic Energy } \\
\text { MeV /A }\end{array}$ & $\beta_{F}$ & $Q_{F}$ & $S_{F}$ & $\begin{array}{c}\text { Current } \\
\text {-amp-part }\end{array}$ \\
\hline Deuterium & +1 & $70 \%$ & 15.0 & .1768 & +1 & $100 \%$ & 525. \\
Carbon & +5 & 61 & 7.5 & .1262 & +6 & 90 & 82. \\
Sulphur & +9 & 34 & 4.7 & .1002 & +14 & 40 & 20. \\
Copper & +11 & 27 & 2.9 & .0782 & +22 & 27 & 11. \\
Iodine & +13 & 20 & 1.65 & .0595 & +31 & 20 & 6. \\
Gold & +13 & 19 & 1.0 & .0463 & +36 & 17 & 5. \\
\hline
\end{tabular}

* Two -Stage Mode - 75\% transmission efficiency. 
$-5-$

Table 3. Booster Ring Parameters

Circumference

Periodicity
$201.84 \mathrm{~m}$

12

Period structure:

$Q H / 2$ O

Q.T/2 $S \quad Q \Delta / 2$ Q

Drifts: 0

$0.6516 \mathrm{~m}$

S

$3.703 \mathrm{~m}$

Phase Advance/Cell

$100.5^{\circ}$

Betatron Tunes, Hand $V$

$\sim 6.7$

Transition Energy, $\gamma_{T}$

6.5

$\beta_{\max } / \beta_{\min }$

16. $/ 2 . m$

$\eta_{\max }$

$1.7 \mathrm{~m}$

Dipole (B): Length

Bending Radius

Apertanve, Hoy (full $)$

$2.4 \mathrm{~m}$

$13.751 \mathrm{~m}$

$3.25 \times 10 . \mathrm{in}^{2}$

Quads (ORle, Qd/2): Halghelugth

$0.25 \mathrm{~m}$

Bore Radius

max. Pole Ti Fid d

4 in

$12.7 \mathrm{KG}$ 
charge limit is reached. This commesponds to a maximum number N.C. of particles that car be injected according to the formula

$$
\frac{N_{\text {s.c. }}}{\varepsilon_{N}}=\left(\beta^{2}\right) \frac{4 \pi B_{p} \Delta_{2}}{3 r_{0} F^{-1}} \frac{A}{Q_{P}^{2}}
$$

where Ef is the bumching factor, derined as the ratio of the average cumpert to the peak currerty $\Delta \nu$ is the maximum aldowable ture depressior, A the mass number, of the charge states,

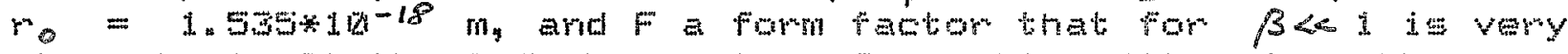
close to 1. At the left-hand side of equation $(d)$, ENis the romalized emittance; the actual emittance is giver by

$$
\varepsilon=\varepsilon_{N} /(\beta y)
$$

Here the enitbances as usual are always given in It is importart that the phase space density $\mathrm{N}_{B} / \varepsilon_{N}$ is as imge as possibleg sine the luminosty ir the coldider deperde om this quertity, provided that no other effects wil calse ever a Etronger limitation than the space charge at injectson in the Booster. The other paraneter the 1 uminosity depende upon is of

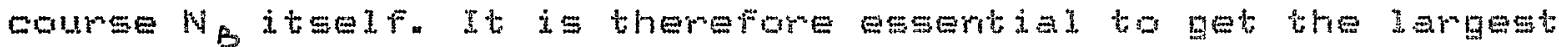
dersity $N_{B} / E_{N}$ and the largest number $W_{B}$ of purticles. Another importent $\equiv$ ide effect is also chet by increasing $N$ one aso increases the rumber of particies that can be trangerered to the coldiden per AcS pulse and reduces the Collider Filing time.

There is some uncertainty to what value to assignto $\mathrm{E}$ f and $\Delta \nu$

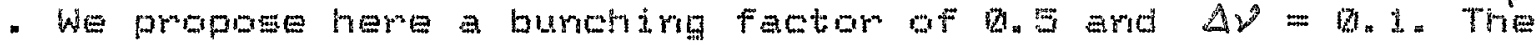
burching factor of 0.5 corresponds to the rf capture process at: irjection ard to the early stage of acceleration in the Bocater. As the beam velocity increases during aceelenation the bunching Factor car be lowered comrespondiridy. The differert species are injected into the Eooster wish no Further strippirg that is with the charge state Go as shown in Table $\Xi$ Table 4 gives the maximum number N s.e. or particles that car be injected with the compepording nomalized emidiance EN" we also give in the same Table the revolution peridod Tres ard the rumber $N_{B}$ of particles with reg turms ingected assuming the beam current values given ir Table $E$. The lamgest rumber of turre that can be efficierity injected in ore plare is taken here to be $y_{9}$ ard this corresponds to a dilution factor as large as $E . E$. By irspectirg Table 4 ore can see that the beam intersity is limited by the Tardem currerts for the lighter ions up to copper. For Copper the Tardem currert output is about the Epace cherge 1 imit at injection into the Eooster. For Iodine ard Gold very clearly there is a space chamge imitation by a factor as iarge as 
Table 4. Bean Intensity, Emittance at Injection into the Booster

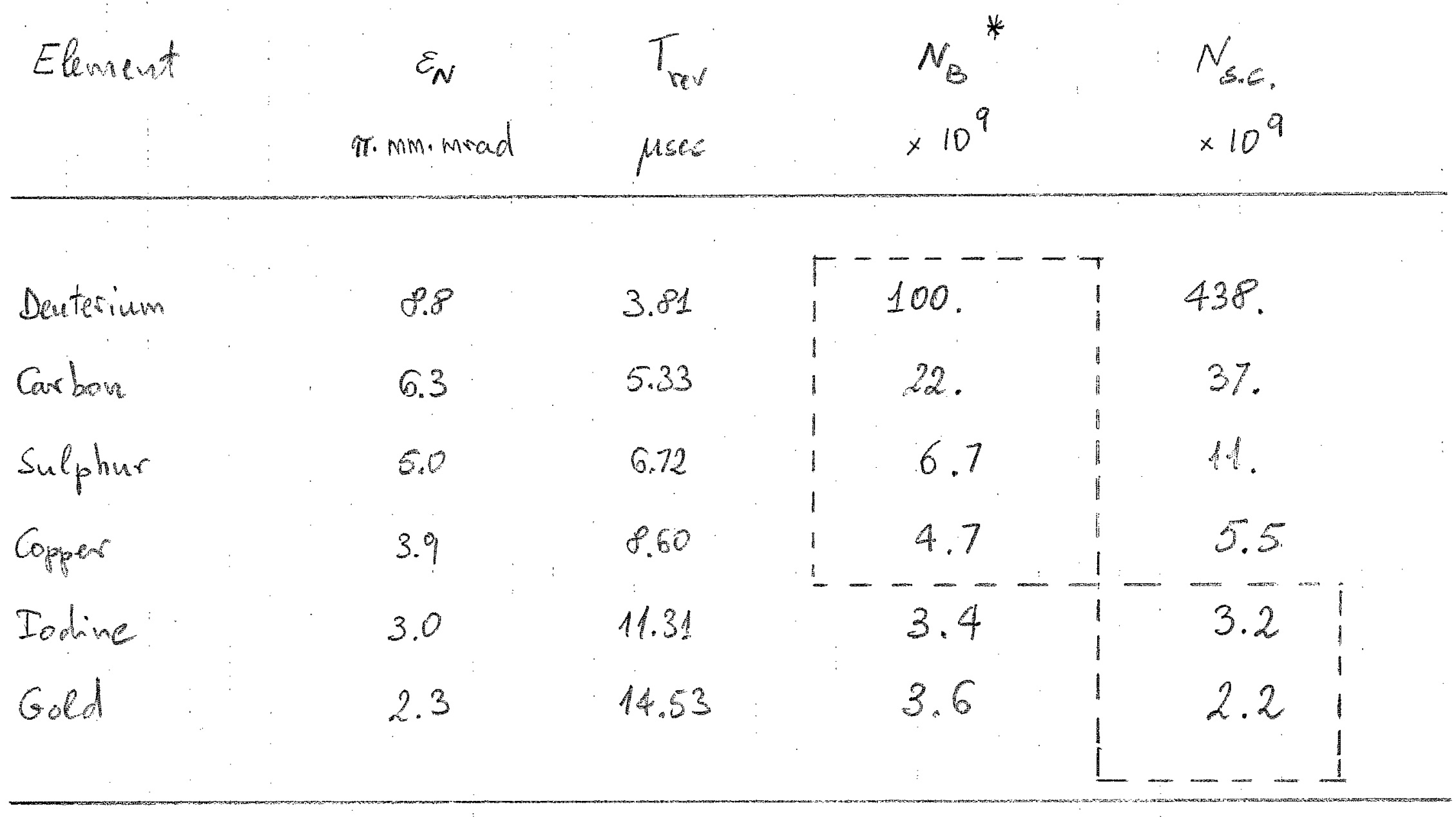

* With 8. turn injection 
Ex The particles numbers inhte dashed squares ame the proposed ores for the estimates ir our echeme. For Gold orily 4 or 5 burns are required to be ir.jected.

The bean is captured at injection by ar hamoric number hat $r$ system; so that only one burch is made ard all the particles given in Table 4 are in this bunoh. The analysis of the ro capture and acceleration is rot given in this note. The acceleretion period is baken to be 0.6 sec for Bold and the overad repetition rate $0 . B$ Hz. Toward the end of the aceseretion the burch is made short enough to match the length of the rf buckets ir the Abs.

Assuming a top field of 12 kg, we have a maximum kinetic energy of 367 MeV/A for Gold whicin comresporids ta $\beta \gamma=2.971$. To minimze the amourt of ro frequency swirg it $i=$ sufficient to accelerate the Iighter ions to the same value which correspords to the fuld acceleration for bold. In this tase the required Frequersy swirg covers the range of $\beta-v a$ ules from b. observe that the ar bean will rever have to crose the Ecoster transition erergy during their acceleration.

A vacum of $10^{-10}$ molig seems to be quite adequate for the aurival of practicaliy all the beam ageinet electron eapture ar 1 ses processes during the acceleration cycles

After extraction from the booster and on their way to the Abs the ions go through ore more Etripping target. The ione injected into the Ags are then completely stripped. We assume a su\% beam loss for bold, Ea\% for lodine and $5 \%$ for Copper ard sulphur. Cambon ard Deuterium do not reed ary further stripping.

\section{The AGS}

The major parameters of the ring are giver in Table 5. birce the injection energy is 367 meV/A and the ions are completely stripped, there is no requirement for improvement in either the vacuum or the of system. The acceler.tor, as it is a muts very well for the acceleration of the ions to the maximum energy.

The scenario that we propose is that ore bunch at the time is trarsferred from the Eocster to the AQS, accelierated to the top energy and ther traneferred so the Colider. The AGS aycle rate is taken to be $0.8 \mathrm{~Hz}$ and that $\mathrm{Q}_{\mathrm{a}} \mathrm{E}$ secords ame needed for the

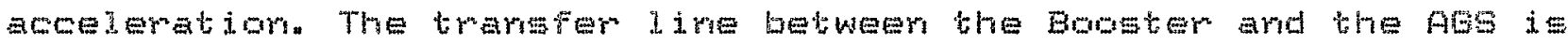
rot discussed here.

We aseune that the final stripping does not cause to sigrificant ircrease in the bean enitumce, therefore, since at the tranefer $\beta \gamma$ $=$ D. 971 the emittance values giver in Table 4 are just about those the beam is ingected with into lhe fos. These enithances are 
$-9$.

Table 5. AGS Parameters

Gircumference

Periodicity

Betalow Tunes, Hamd V

Tramsition Enevgy, $\gamma_{T}$

Betatron Acceptance

Injection Energy (proton)

Ejection Energy (pratom)

RF Frequency

Harmouse Namber. h

Peak RF Volage

Maguetic Rigidity, Bp

at extraction
$807.11 \mathrm{~m}$

12

$\sim 8.7$

P.S

$\sim 30 \pi \mathrm{mm} \cdot \mathrm{mrad}$

$200 \mathrm{HEV}$

28.62

$2.50-4.457 \mathrm{MH}$

12

300. KV

$96.5 \mathrm{kG} \cdot \mathrm{m}$ 
corsiderably emaller thar the ming betatror acopobares.

There is some uncentainty to whet value to assign to bhe beam longitudiral enittarice. The figures that commesond to irgection into the Boweter are very smali, but we expect gome diation during the capture process and the acceleration cycle. A realistic estimate is probably $b_{n} \geq$ ev/A-sec, ard we will use this figure as

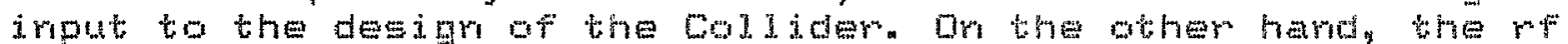
buckets in the AGS ane the smallest at injection if we aseume a

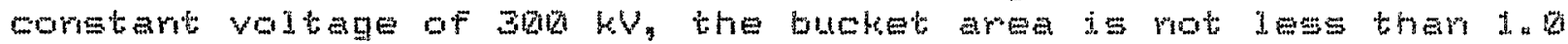
EV/A-sec.

At the end of the acceleration in the AQs, the bunch of $i$ ore is taylored so that it wili fit ineide ore of the rif buctede in the Col1ider. For this pumpose we take a fimel total bumch length of 14 ramosec.

At thim point, orce the ion burch has been ejected frow the Abs, the Souree of ions ende its furction. 
THE GOLLTDER

In this section we describe orly the input parameterse for the design of the Collider.

The two transfer ines that correct the AGS to the two magretic rirge are part of the Colidier system, but they will rot be described here. The two ringe and the trarefer lires will be acconodated in the CEA tumele that already exict an 01 te. Thus the ize of the coldider is given and waches the eize of the cea turine 1 .

Each ior burch accelerated in the AGS is extracted and tharsferred to ore of the two Colider Rings. The burch is eapured by a stationary rf bucket stariding by. It is exential that the shape of the burch prior extraction from the AGS is taylored to mesto the shape of the buckets ir the coljider" majom paramerers of the Colidder Ringe are given in Table E.

Eeam parameters at injection are given in Tabie 7 . it is msomed that because or al the required menipolations the betatrom enjttareses and the longitudinal phase space area are fomewhat diluted to the final values shown in Table 7 ard baken to be the same for all species, with the exception of protomen

The burch area, $S_{3}$ and the beam enittance, $\varepsilon$, are defined for $95 \%$ of the beem population

$$
S=6 \pi \sigma^{\infty} \sigma_{E}
$$

where $\sigma_{\tau}$ is the rms bunch lemath in urit of time end $\sigma_{E}$ bhe rms Emergy spread:

$$
\varepsilon=6 \pi \frac{\sigma_{H_{1} V}^{2}}{\beta_{H_{1} V}}
$$

wheme $\sigma_{H, V}$ is the rms beam width or height and $\beta_{H, V}$ the horizomal or vertical amplitude lattice functions the relation between the actual enitiance and the nomalized emitance is given by eq. 6 ).

The number of the ione per eam burch tharfermed to the Collidem is also giver in Tabie 7. It was demived from Table 4 atrar 
adjusting for the losese between the Eooster and the ADS. Assuming a maximurim rigidity of $839.5 T-m$ we give, aleo ir Table 7 , the maximum kinetio energy that can be reached in the Collider Rirgs.

The two mings are filled in the box-cer fashin. The totel number af bunches accepted is 57 per ring ar equivalert mumber of AQS pulses is required which gives a Filling time of a litsle more than one mirute per ring. The sitution is differemi for the proton beam siree $1 \mathrm{e}$ burches car be accelerated at the same time in the AGS; thus arily five fles pulses would be required ard the filing time is less than ten secords.

The burch separation is 67 meters and this correspords to a rise time of ebu rano-sec for the ingection kickers.

The two magretic ring have a horizortal lay-out, side by sicen, with a separation of $24 \mathrm{~cm}$ between the two bean axis. The periadicity is threerold. 
$-13=$

Table 6. General Parameters for the Colder

Circumference

Revolution. Frequency $(\beta=1)$

Filling Hole

No. of Bundes/Ring

Filling Time / Ring

Periodicity

Magnetic Rigidity, Bp:

at injection

at top energy
$3833.0 \mathrm{~m}$

$78.1972 \mathrm{kHz}$

Box-Cor

57

$\sim 1$ minute

$3(6)$

9.65 To

$839.5 \mathrm{~T}-\mathrm{m}$ 
Table 7. General Beam Parameters for tide Collider

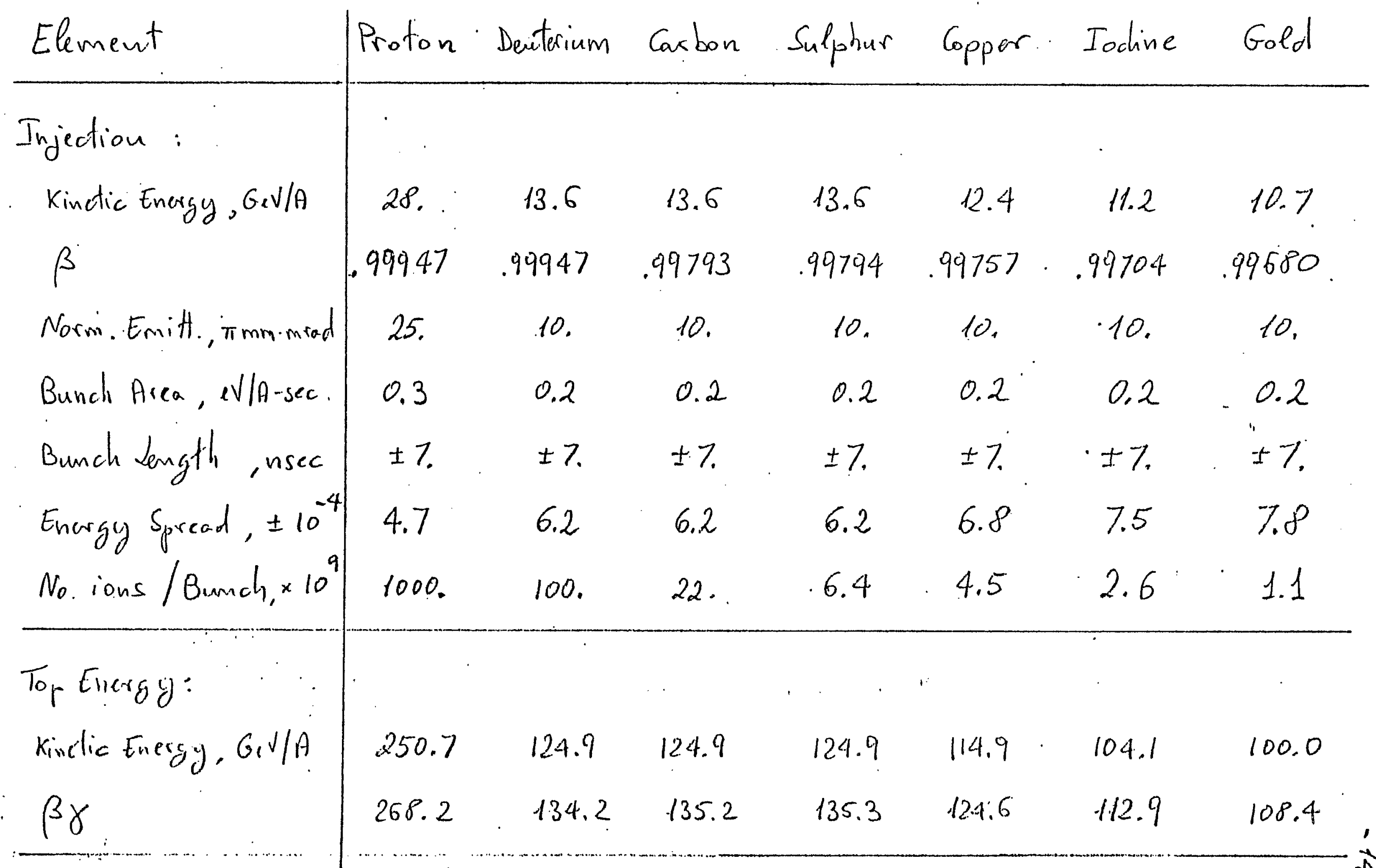

